\title{
Attention Deficits in Dyslexia: Evidence for an Automatisation Deficit?
}

\author{
Elisabeth Moores ${ }^{1}$, Roderick I. Nicolson ${ }^{2}$ and Angela J. Fawcett ${ }^{2}$ \\ 1. Neurosciences Research Institute, Aston University, Aston Triangle, Birmingham, B4 7ET, UK \\ 2. Department of Psychology, University of Sheffield, Western Bank, Sheffield, S10 2TP, UK
}

RUNNING TITLE: ATTENTION DEFICITS IN DYSLEXIA

Elisabeth Moores, Neurosciences Research Institute, Department of Psychology, Aston University, Aston Triangle, Birmingham, B4 7ET, UK

Email:e.j.moores@aston.ac.uk

Fax: +44 (0)1213593257

Tel: $+44(0) 1213593611$ 


\begin{abstract}
Both attentional difficulties and rapid processing deficits have recently been linked with dyslexia. We report two studies comparing the performance of dyslexic and control teenagers on attentional tasks. The two studies were based on two different conceptions of attention. Study 1 employed a design that allowed three key components of attention focusing, switching and sustaining - to be investigated separately. One hypothesis under investigation was that rapid processing problems - in particular impaired ability to switch attention rapidly - might be associated with dyslexia. However, although dyslexic participants were significantly less accurate than their controls in a condition where they had to switch attention between two target types, the nature of the deficit suggested that the problem was not in switching attention per se. Thus, in Study 2, we explored an alternative interpretation of the Study 1 results in terms of the classic capacity-limited models of 'central' attention. We contrasted two hypotheses: (a) that dyslexic teenagers have reduced cognitive resources versus (b) that they suffer from a general impairment in the ability to automatise basic skills. To investigate the automaticity of the shape recognition component of the task a similar attention paradigm to that used in Study 1 was employed, but using degraded, as well as intact, stimuli. It was found that stimulus degradation led to relatively less impairment for dyslexic than for matched control groups. The results support the hypothesis that dyslexic people suffer from a general impairment in the ability to automatise skills - in this case the skill of automatic shape recognition.
\end{abstract}

Keywords: attention, attention shifting, attention deficit hyperactivity disorder, dyslexia, learning disability, rapid processing, automatisation, resources 


\section{Introduction}

Developmental dyslexia was defined by the World Federation of Neurology (1968) as "a disorder in children who despite conventional classroom experience, fail to attain the language skills of reading, writing and spelling commensurate with their intellectual abilities". The DSM IV (American Psychiatric Association, 1994) diagnostic criteria for the diagnosis of 'reading disorder' includes "reading achievement, as measured by individually administered standardised tests of reading accuracy or comprehension, is substantially below that expected given the person's chronological age, measured intelligence, and ageappropriate education". Dyslexia is thought to affect around $4 \%$ of the population (Badian, 1994; Jorm, Share, Maclean and Matthews, 1986).

The dominant cognitive level analysis of dyslexia has for many years now been in terms of a phonological deficit (see e.g. Snowling, 1987; Stanovich, 1988; Vellutino, 1979). However, more recently, alternative theories have been proposed which, although consistent with phonological problems, also suggest problems occur outside the phonological domain (see e.g. Fawcett and Nicolson, 1994 for an overview). In addition, for many years there have been reports of attentional problems in dyslexia. It is a common clinical observation that dyslexic children can have difficulty 'keeping on track' (Augur, 1985). Furthermore, it has been estimated that around $15 \%$ of children with dyslexia also have attention deficit hyperactivity disorder (ADHD) and around 36\% of children with ADHD are estimated to have dyslexia (Shaywitz, Fletcher and Shaywitz, 1994).

One of the difficulties in distinguishing between different cognitive level accounts of dyslexia arises from a lack of wide-ranging data about the cognitive symptoms. Much of the cognitive research has focused either on the phonological or literacy performance (in which the extant theories make similar predictions), or on aspects of sensory processing. The objective of the studies reported here was to investigate the performance of dyslexic teenagers on attention tasks, with the intention to first establish which components (if any) of attention cause difficulties for them, and then to consider the implications of these findings for the theoretical understanding of dyslexia.

\section{Theoretical approaches to attention}

One of the difficulties in studying attention is that it is a concept that is easy to grasp intuitively but difficult to define or test objectively. Though attention is a central and seminal 
concept in cognition, there is no completely accepted model of its components or processes, and little consensus as to how they should be identified. Early work (e.g., Norman, 1968; Kahneman, 1973) originated from Broadbent's concept (1958) that attention was a method of coping with the limited 'capacity' of the human information processing system - a means of directing 'resources' to key tasks. However, following a series of critiques of the capacity concept (Allport, Antonis and Reynolds, 1972; Navon, 1984), this unitary resources framework was largely replaced by new ones attempting to distinguish between different components of attention (e.g. Posner and Petersen, 1990; Mirsky, Fantie and Tatman, 1995). It should be noted that the 'resources' and componential frameworks of attention might be seen as complementary rather than competing, with the resources framework being seen as a cognitive level description of the effects of processing load on 'focus' and 'sustain' components of attention. In most cognitive tasks the different components of attention work seamlessly together. In reading, attention has to be switched and focused alternately whilst moving fixation from word to word. It may therefore be, for example, that the established deficit in dyslexia in speed on the rapid automatised naming tasks (Denckla and Rudel, 1976; Wolf and Bowers, 1999), in which the subject has to name a card full of common pictures or colours, arises not from a problem in either focusing or maintaining attention, but a slower speed of switching attention.

In a long-established approach to developmental dyslexia, Nicolson and Fawcett (1990) established that dyslexic children suffered from lack of automaticity even outside the language domain (and hence needed to input greater 'resources' in order to achieve normal performance on many tasks). In a recent article in this journal (Nicolson and Fawcett, 2000) they demonstrated how the automatisation deficit account provides an excellent cognitive level description of most of the symptoms of developmental dyslexia. The automaticity framework is also espoused by Hazell et al (1999), who suggested that children with specific learning disorders (significantly lowered reading, arithmetic or spelling score) might have a deficit in innate automatic processing. As they point out, 'It is not difficult to imagine how such an impairment might affect the capacity to correctly identify some letters, numbers, symbols and perhaps even words'.

Interestingly, the automatisation deficit hypothesis was put forward before the componential approach to attention was established. Consequently, an important theoretical issue is whether well-established problems in automatisation might in fact derive from some component of the attentional system, or indeed whether some specific component of attention 
is impaired in dyslexic people in addition to their difficulties with automatisation. To our knowledge, no researcher has ever undertaken a systematic analysis of componential and of central attentional (resources) processes in dyslexia. The automatisation deficit account holds that the problems arise within 'central attention'. By contrast, a number of alternative formulations, in particular those involving some kind of sensory processing deficit, might predict problems relating to specific components of attention, for example the speed of switching attention. Consequently, in Study 1 we used a simple 'componential' analysis, looking at switching, focusing and maintaining attention.

Although Posner's 'componential' framework is typically investigated using spatial cueing tasks, there is already intriguing evidence that dyslexic people may have abnormalities in spatial attention (e.g., Facoetti, Paganoni and Lorusso, 2000). Thus, in order to avoid any potential confound from anomalies in spatial attention, we decided to use a task in which no eye movements were required, with only one item presented, centrally on the screen.

Given the length of this paper, and the complexity of the issues studied, we consider it may be valuable to precede the detailed accounts of method and findings with an overview of the findings and the design logic of the two studies. In brief, results from Study 1 suggested that the attention switching mechanism appeared to be working normally in dyslexia, but that dyslexic participants were nevertheless adversely affected by continual target switches. We concluded that the problem must instead arise in central attention. In an attempt to establish the underlying cause of this problem, we devised Study 2, which allowed two hypotheses to be distinguished: (a) that the central attention problem arises from lower general capacity (the resource limitation hypothesis); and (b) that the problem arises from an automatisation deficit. The results of Study 2 favoured the latter hypothesis. The combination of studies, investigating attention both from a componential perspective and from a resources perspective, is unique in the dyslexia literature.

\section{Introduction to Study 1}

Three key aspects of selective attention are; ability to sustain attention over a period of time, ability to attend selectively to one stimulus, and ability to shift attention at will from one stimulus to another. A systematic approach to the investigation of potential attentional deficits in people with dyslexia would examine these abilities, not just in terms of performance accuracy, but also in terms of the time course of the attentional processes. Several previous studies have investigated various aspects of attention (and its timing) in 
different populations including children with ADHD and children with good and poor reading skills (e.g. Brannan and Williams, 1987; Dykman, Ackerman and Oglesby, 1979; Fischer and Weber, 1990; Hallahan, Kauffman and Ball, 1973; Milberg, Whitman and Galpin, 1981; Pearson and Lane, 1990; Pelham, 1979). More recently, studies have also focussed on attention and dyslexia more specifically, arguing for differences in attentional dwell time (Hari, Valta and Uutela, 1999), the spatial distribution of visual attention (Facoetti, Paganoni and Lorusso, 2000), asymmetric distribution of attention over the two visual fields (Facoetti and Turatto, 2000) and automatic covert orienting and sustained focusing of attention (Facoetti, Paganoni, Turatto, Marzola and Mascetti, 2000).

Evidence of deficits in dyslexia in processing speed, timing, and speed of stimulus classification, coupled with evidence of an attentional deficit, suggest the hypothesis that at least some of these difficulties could be attributable to a deficit in rapid orientation and shifting of attention. In support of this in the spatial domain, Brannan and Williams (1987) found differences between adults and children with good or poor reading skills on Posner's spatial cueing task, but only at very rapid SOAs. See also Everatt (1999) for a series of reviews of visual processes in dyslexia. In addition, Facoetti, Paganoni, Turatto, Marzola and Mascetti (2000) found that dyslexic children did not show the expected validity effect on Posner's spatial cueing task at either of the SOAs which they used to elicit automatic orienting of attention (136ms and $238 \mathrm{~ms}$ ), although in a second experiment found voluntary covert orientation of attention (at SOAs of $504 \mathrm{~ms}$ and $1000 \mathrm{~ms}$ ) of dyslexic children to be equal to that of their controls. It is therefore possible, that the processing speed of stimuli in dyslexic people is normal once attention has been allocated to them, but that this allocation takes longer than usual.

Experiments presented here test non-spatial attention shifting and focussing of attention; attention directed to a particular target in a paradigm in which all stimuli are presented sequentially in the same position. Since it has been shown that dyslexic people seem to have a different spatial distribution of attention (e.g. Facoetti and Molteni, 2001; Facoetti, Paganoni and Lorusso, 2000; Facoetti, Paganoni and Lorusso, 2000), using a non-spatial task precluded this potential confound. Issues addressed in Study 1 were therefore whether dyslexic teenagers had deficits in (i) selective attention/ focus attention (ii) shifting attention in particular rapidly shifting attention; and (iii) sustained attention. These issues were investigated using a paradigm developed by Akshoomoff and Courchesne (1994) who identified a specific rapid attention shifting deficit in (four out of five) young patients with 
damage to the cerebellum. Study 1 therefore used Akshoomoff and Courchesne's (1994) paradigm to compare teenagers with dyslexia and their controls on one 'shift attention' and two 'focus attention' tasks. In the focus conditions, participants had to respond to a prespecified target shape in a constant stream of distractor shapes (which appear singly in the centre of a computer screen) whilst ignoring the others. In the shift condition, the participant had to again respond only to the designated target shape, ignoring distractors, but in this case the target shape alternated following each correct response. Upon a correct response to the first target shape, the target switched to the alternative shape, and the first target shape had to be ignored, and so on. The paradigm is therefore of particular interest in that it provides a method of dissociating the three different components of attention; focus, shift and sustain. Furthermore, by analysing performance in terms of the interval between each stimulus and the time since the previous response was made, Akshoomoff and Courchesne established that their group of cerebellar patients had a deficit only for the shift attention condition, and then only for rapid attentional switches (i.e. when the interval time from the previous target was under 2.5 seconds). Similar analyses were performed in our Study 1.

\section{Study I: Method}

\section{Participants}

Participants were recruited from the University of Sheffield's panel of dyslexic and control subjects, and had all taken part in experiments over a period of some years. All the participants were white, drawn from social classes 1,2, and 3 (i.e., middle class or skilled working class), and included both males and females. All participants with dyslexia on this panel were recruited at age 7-10 from a local school for children with literacy problems, via the local Dyslexia Institute, and via referral from the British Dyslexia Association helpline. Criteria for inclusion in the dyslexic panel were: discrepancy of at least 18 months between chronological and reading age; together with a full scale WISC-R/WISC III IQ (Wechsler, 1976, 1992) of at least 90 at diagnosis, without known primary emotional, behavioural or socio-economic problems, according to psychologists' reports. Standard scores for reading at diagnosis ranged from 65-92, mean 78 on the tests of single word reading (Wechsler, 1993). There was no selection criteria other than those outlined above - anybody eligible was included. Control participants were matched with the dyslexic groups overall for chronological age and IQ, had no previous history of reading difficulties, and read at worst within 6 months of their chronological age. All of the participants therefore had some experience in experimental procedures and were familiar with both the surroundings and the experimenter. 
Two age groups took part in this study, and we shall refer to the 14 and 18 year old groups with dyslexia as D14 and D18, with the two corresponding normally achieving groups as C14 and C18 respectively. Psychometric details (see Table 1) are based on full psychometric assessments for the participants with dyslexia, and standard short-form IQ tests (Vocabulary, Similarities, Block design and Picture completion) for the control participants. These were obtained around 2-3 years prior to the study, because it is not good practice to retest IQ regularly.

Participants had also all been assessed for clinical evidence of ADHD in accordance with the Diagnostic and Statistical Manual of Mental Disorders: $3^{\text {rd }}$ edition (DSM IIIR: American Psychiatric Association, 1987) ${ }^{1}$. All participants were screened for ADHD by parents report and experimenter's evaluation. A score of at least 8 out of 14 markers of the disorder is required for clinical diagnosis. Mean scores for the groups are also shown in Table 1. None of the participants showed evidence for ADHD, and there were no significant differences between the score of the two groups. Only three of the dyslexic group scored 4 or more on the DSM-III R ADHD scale ${ }^{2}$.

The groups consisted of fourteen participants (11 males, 3 female) with dyslexia and fourteen normally achieving control participants (8 males, 6 females). Table 1 shows mean reading/spelling age for each group as assessed at the time they performed this experiment.

However, two younger control participants were omitted from the experiment (data not included in Table 1). One of these could not complete the experiment owing to apparent (self-reported) visual problems, another had unusual results which suggested that he tested the computer program to its limits by producing strange combinations of responses (e.g. what happens if the mouse is held down, if I click twice during the same trial and so on). These responses resulted in the stalling of the program and had created discrepancies between the actual and the desired interstimulus intervals.

\footnotetext{
1 At the time the psychometric data for these participants were collected, there was considerable unease in the UK regarding the specificity of the DSM-IV criteria for attentional deficit (Reason, 1999), and consequently we used the established DSM-III criteria.

2 These three participants all have severe reading difficulties and problems with their memory and organisation. They all have problems with following instructions and losing things because their memories are poor. Two of them talk excessively, because they have forgotten the instructions and are seeking clarification, they are easily distracted because they need to put in extra effort to prevent themselves failing, and they become embarrassed and fidgety when they do fail.
} 
All participants were given $£ 3$ for their co-operation.

\section{[TABLE 1 ABOUT HERE]}

\section{Design}

As in Akshoomoff and Courchesne's design, there were three conditions:

i) Focus condition 1 (350 trials):

TARGET: white ovals (thus: attend shape)

ii) Shift condition (700 trials):

TARGET: white ovals and dark blue squares alternately

iii) Focus condition 2 (350 trials):

TARGET: dark blue squares (thus: attend colour)

Akshoomoff and Courchesne's repeated measures design was replicated, except that all participants experienced the conditions in the same order. This ensured that all participants had the same experience and that differences between groups could be more confidently ascertained. To allow investigation of the time required to either shift attention (in the shift condition) or re-engage attention after a response (focus conditions), four different interstimulus intervals were used, with trials determined following a (pre-determined) pseudorandom order. Independent variables were therefore: group (dyslexic/ control), age group (14/18 years), condition (focus/ shift) and time since last target (continuous variable: the wide range of different values were subsequently divided into various time bins for statistical analysis).

\section{Procedure}

The study was carried out on an Apple Macintosh computer with software designed to replicate the Akshoomoff and Courchesne procedure. Additional analysis software was used to categorise the results into various time periods since the last correct hit.

In brief, the computer presented a long sequence (350 in the focus conditions or 700 in the shift condition) of shapes (white oval, white circle, dark blue square and light blue square) singly (at a mean rate of just over one per second) on the screen. Shapes occurred with different probabilities, with potential target shapes (white oval and dark blue square) being less frequent (15\% probability of occurrence each) than distractor shapes (35\% probability of occurrence each). Four possible interstimulus intervals (ISIs) were presented randomly between stimuli (200, 400, 600 and 800 milliseconds). Stimuli and ISIs occurred in the same 
pseudorandom order for each participant; the random aspect of the data was important only to preclude anticipatory responses to stimuli and to create a variety of time periods between targets. However, despite the identical sequence of stimuli and ISIs in each condition, in the shift condition, any misses would result in different inter-target intervals for each person. This is because following a miss to a target, the current target would remain the same rather than switching, thereby effectively changing the sequence for each person.

Participants were instructed to ignore non-targets and respond to a specified target by pressing the mouse button. The target differed between conditions. In focus attention conditions, the target remained the same throughout the conditions (white oval in focus condition 1, dark blue square in focus condition 2: thus conditions which could be performed by attending to shape only and colour only respectively), whereas in the shift attention condition, the target alternated between two possibilities (white oval and dark blue square). If targets were missed, then the target remained the same. Responses were recorded as hits if they came within $1000 \mathrm{~ms}$ of the target and were acknowledged as such by a short tone. In all conditions hits, misses, correct rejections and false alarms (FAs) were recorded.

Participants were told that the computer would flash up various different shapes on the screen and that depending on the condition, they should press the mouse as fast as they could when they saw a particular shape. No specific instructions were given on the relative importance of speed and accuracy. They were then given a 10 trial practice for the first condition which took them through the whole procedure and gave them direct feedback ("well done", "that was the target, you missed it" and so on). The main experiment followed the same procedure except that the stimulus durations and interstimulus intervals were shorter than in the practice (as detailed above) and that the only feedback was a short tone from the computer when a target was correctly detected. The first focus condition followed, in which participants were asked to respond to white ovals only. A 20 trial practice for the shift condition followed the first focus condition (longer in order to ensure that participants fully understood the procedure). It guided participants through the whole procedure with comments like "Well done. Now the target switches to the dark blue square". The shift condition then followed after a reminder of the instructions to respond to dark blue squares and white ovals alternately. Finally the second focus practice and condition were presented in which participants were asked to respond to dark blue squares only. The whole experiment lasted around thirty minutes. There was no objective procedure employed to ensure that the children were watching the sequence, although the experimenter watched each child perform the tasks. 
The software was a close replication of Akshoomoff and Courchesne (1994). Differences included: (i) Increased probability of a target stimulus (15\% instead of 12.5\%), (ii) Increased duration of all stimuli (250 milliseconds instead of 50 milliseconds), (iii) Different ISIs, (iv) 350 stimuli were given in a single block in the focus conditions and 700 in the shift condition, rather than splitting conditions into either 5 or 10 blocks of 80 stimuli, (v) Main experiment trials were not dependent on any success rate in the practice trials, (vi) A short tone indicated a correct hit and a reminder to switch to the other target, (vii) The focus conditions were not counterbalanced, (viii) Responses counted as hits if they came within 1000 milliseconds (instead of 200 to 1400 msecs) of the target, even if subsequent shapes had been and gone at that point, this alteration from the Akshoomoff and Courchesne procedure therefore reduced the risk of counting FAs as hits and we felt that it was appropriate since participants with cerebellar damage might be expected to have severe motor impairments which we would not expect in our samples, (ix) Akshoomoff and Courchesne's analysis used percentage correct hits rather than a d' measure of accuracy.

\section{Analyses}

A critical component of the Akshoomoff and Courchesne design was the analysis in terms of the time since the last target was hit. For instance, in the shift attention condition, if a target appeared only 1 second after the previous target, then a rapid attention shift was required to detect both correctly. In the present experiment finer-grained temporal analyses were performed using 8 time bands (zero to 1, 1-2, 2-3...6-7 and $>7$ seconds). Due to the random aspect of the target order, the random interstimulus intervals, and the individual differences between successfully detected targets, the time since the last correct hit for each trial is not a member of a discrete set of values. Akshoomoff and Courchesne chose to divide their scale into five time bands in order to examine accuracy and speed of attention shifting in their participants. In their analysis, rapid attention shifting was defined as 'from 0.4 to 2.5 seconds since the last target'. Other time bands used were; 2.5-4.5, 4.5-6.5, 6.5-10.5 and 10.5 to 30 seconds. We wanted a finer tuned analysis, with the ability to examine rapid attention shifting in a shorter time period than 2.5 seconds

To perform this analysis, for each participant the time since the last correct hit occurred was calculated for every stimulus regardless of the response. Stimuli were then categorised according to the time since the last hit. The proportions of hits and FAs for each time 
category were then calculated for each person. The proportion of hits refers to the probability of a hit given a target (i.e. the number of hits divided by the number of possible hits); ideally $100 \%$. The proportion of FAs refers to the number of FAs given a non-target (i.e. the number of FAs divided by the number of possible FAs); ideally $0 \%$. This information was used to obtain the d' measure of accuracy (from signal detection theory ${ }^{3}$ for each time category by finding the $\mathrm{z}$-value for each proportion (a negative value for proportions under $50 \%$ and a positive value for proportions over 50\%). To calculate d', the $\mathrm{z}$-value corresponding to the proportion of FAs was subtracted from that of the proportion of hits. Hit latencies were analysed in the same time categories.

\section{Results}

As noted earlier, each participant undertook three conditions, two 'focus attention' conditions and one 'shift attention' condition. Three-factor repeated measures ANOVAs were carried out on each condition separately to investigate the factors of group, age, and time since last hit. The dependent variables of accuracy (d') and reaction time (s) were analysed separately. We recommend employing a degree of caution in the interpretation of results from this study, particularly with regard to null effects, since sample sizes were relatively small.

\section{Accuracy}

For each condition, mean accuracy data and the mean percentage of hits and FAs are presented in Table 2. It may be seen that the overall performance accuracy was high, especially for the D18 and C18 groups.

[TABLE 2 ABOUT HERE]

\section{a) Accuracy in focus attention conditions}

Figure 1 shows the mean group accuracy on focus condition 1 (attend shape). It can be seen that dyslexic performance is slightly lower than control performance. However, accuracy in focus condition 1 did not produce a significant difference between groups $\left(F_{1,24}=2.80\right)$ and there were no significant group-by-age $\left(\mathrm{F}_{1,24}=0.44\right)$ or group-by-time $\left(\mathrm{F}_{7,168}=1.18\right)$ interactions. Figure 2 shows the mean group accuracy on focus condition 2 (attend colour). Similarly, there was no group effect $\left(\mathrm{F}_{1,24}=0.32\right)$, and no group-by-age $\left(\mathrm{F}_{1,24}=0.27\right)$ or, more

3 Using the standard formula (Swets, 1964): $\mathrm{d}^{\prime}=\mathrm{Z}$ (Yes/Target) - Z (Yes/ Non-Target). This d ' measure is technically a measure of sensitivity, taking into account hits, misses and FAs. We use the term accuracy here in 
crucially, group-by-time $\left(\mathrm{F}_{7,168}=1.125\right)$ interactions in this condition. However, there were significant main effects of age in both focus conditions 1 and 2, with the younger groups being less accurate than the older groups $\left(\mathrm{F}_{1,24}=19.61, \mathrm{p}<0.001\right.$ and $\mathrm{F}_{1,24}=4.93, \mathrm{p}<0.05$ respectively).

A further set of three-factor ANOVAs (group, age, and shape of stimulus as independent variables and the number of FAs made as the dependent variable) were carried out in each condition to investigate the cause of the age effects further. In focus condition 1, a highly significant main effect of shape was found $\left(\mathrm{F}_{2,48}=17.75, \mathrm{p}<0.0001\right)$, suggesting that FAs were not randomly allocated amongst the four shapes. This ANOVA also elicited a trend towards an effect of age $\left(\mathrm{F}_{1,24}=4.06, \mathrm{p}=0.06\right)$ and a significant age-by-shape interaction $\left(\mathrm{F}_{2,48}=5.74\right.$, $\mathrm{p}<0.01)$. Such effects of age were not found in either of the other conditions. Analysis of the FAs for each shape suggested that the age effect was particularly apparent in the focus condition 1 because the younger participants were more likely than the older ones to respond to white circles instead of white ovals.

[FIGURES 1 AND 2 ABOUT HERE]

\section{b) Accuracy in the shift attention condition}

In contrast to the focus conditions, in the shift condition there was a significant main effect of group on accuracy $\left(\mathrm{F}_{1,24}=5.20, \mathrm{p}<0.05\right)$, with dyslexic participants having lower accuracy. Although an age trend also emerged $\left(\mathrm{F}_{1,24}=3.52, \mathrm{p}<0.1\right)$, with younger participants being less accurate (see Table 2), there were no significant group-by-time or group-by-age interactions $\left(\mathrm{F}_{7,168}=1.60\right.$, n.s., $\mathrm{F}_{1,24}=2.01$, n.s.; see Figure 3$)$. The lack of any group-by-time interaction in either the shift or the focus conditions suggested that any differences between dyslexic and control groups were not due to either rapidly shifting (in the shift condition) or rapidly reengaging (in the focus conditions) attention.

However, our dyslexic groups had slightly higher (though sub-threshold) ADHD scores (n.s.) and, in the younger age group, slightly lower IQ scores. It was therefore of interest to attempt to exclude effects of these differences from the main group effect found in the shift condition. To do this, the same ANOVA as above was performed including ADHD and IQ scores as covariates. Whilst ADHD score did not account for a significant amount of variance in the 
model $\left(\mathrm{F}_{1,22}=2.52\right)$, the effect of IQ was significant $\left(\mathrm{F}_{1,22}=8.65, \mathrm{p}<0.01\right)$. An investigation of this effect showed a strong positive correlation between mean performance on the shift condition and IQ score. The effect of group was reduced to a trend $\left(\mathrm{F}_{1,22}=3.14, \mathrm{p}=0.09\right)$ likely to be partly due to removal of covariate effects and partly due to loss of degrees of freedom from the analysis ${ }^{4}$. The group-by-age interaction was also enhanced to significance $\left(\mathrm{F}_{1,22}=6.31, \mathrm{p}<0.05\right)$, reflecting the smaller difference between the young and old dyslexic groups compared to their controls.

[FIGURE 3 ABOUT HERE]

\section{Reaction Times}

Mean RTs are shown in Table 3. It may be seen that the groups with dyslexia did have slightly longer mean RTs than those of the normal achieving groups in all three conditions. These differences were significant only in the shift attention conditions, although this dissociation may at least in part been due to lack of statistical power. Separate three-factor repeated measures ANOVAs were again performed on each condition separately to investigate the factors of group, age, and time since last hit on RT. Some participants' RT data could not be fully analysed, however, due to missing data points where they had not made any hits at all in a particular time category5.

[FIGURE 4 ABOUT HERE]

\footnotetext{
4 It should also be noted that since, admittedly, dyslexic groups did have higher ADHD scores than controls, covarying for effects of ADHD may have also removed some of the main group effect. Since this experiment was not designed to examine sub-threshold effects of ADHD it is thus difficult to dissociate effects of group and effects of sub-threshold ADHD symptoms with any precision - a more complex design would be required to do this.

5 This occurred particularly in focus condition 1, possibly owing to either fewer possibilities in this condition because of the random aspect of the time periods, or to practice effects (so that participants were correctly responding to more targets in the second focus condition). It is therefore possible that the participants with the lowest accuracy were omitted from the hit latency analysis. The fact that the $F$ value changes very little between the two focus conditions, however, despite the large increase in included subjects (as can be seen by the degrees of freedom), suggests that this factor had little effect on the results. Because of this difficulty and the similarity of each person's RTs in each condition, it was also not possible to perform a four factor ANOVA (including the factor of condition) on the data due to singularity in the data.
} 


\section{a) $\quad$ RT in focus attention conditions}

Analyses revealed that, although dyslexic groups' RTs were slightly slower, group RTs were not significantly different in focus condition $1\left(\mathrm{~F}_{1,11}=2.71\right.$, n.s. $)$, and that there were no significant group-by-age interactions $\left(\mathrm{F}_{1,11}=0.03\right)$ or main effects of age $\left(\mathrm{F}_{1,11}=1.72\right.$, n.s. $)$. Similarly, there were no main effects of group $\left(\mathrm{F}_{1,23}=2.87\right.$, n.s. $)$ or group-by-age interactions $\left(F_{1,23}=0.00\right)$ in focus condition 2. A main effect of age did emerge $\left(F_{1,23}=5.76, p<0.05\right)$, with younger participants being slower than older ones.

\section{b) RT in the shift attention condition}

In the shift attention condition, there was a significant main effect of group on $\mathrm{RT}\left(\mathrm{F}_{1,22}=\right.$ 6.67, $\mathrm{p}<0.05$ ), with the normally achieving groups recording faster RTs. There were no group-by-age or group-by-time interactions, or main effects of age $\left(F_{1,22}=0.00, F_{7,154}=0.98\right.$ and $F_{1,22}=2.64$ respectively). Covarying for IQ and ADHD led to an enhancement of the main group effect $\left(\mathrm{F}_{1,20}=9.65, \mathrm{p}<0.01\right)$, but no other effects were significant. As a factor in the model, ADHD showed a trend towards significance $\left(\mathrm{F}_{1,20}=3.21, \mathrm{p}=0.08\right)$.

\section{[TABLE 3 ABOUT HERE]}

\section{Sustained Attention}

It was considered whether the lower performance of the groups with dyslexia could be due to boredom factors and increased difficulty in sustaining attention over the 15 minutes required by the shift attention condition, in contrast to the 7 or 8 minutes required by each focus condition. In order to ensure that differences between groups' accuracy was due to difficulty with the task itself, rather than any difficulty for the group with dyslexia in being unable to keep attention on task for the time period, we compared groups' performance over the first and second halves (first 350 stimuli and second 350 stimuli) of the shift attention task. For this a four factor ANOVA was used; investigating effects of group, age, time since last hit and half (first or second). Again, the main effect of group was significant $\left(\mathrm{F}_{1,22}=5.16\right.$, $\mathrm{p}<0.05)$. There was also a highly significant effect of half $\left(\mathrm{F}_{1,22}=10.18, \mathrm{p}<0.01\right)$ (with lower accuracy in the second half), but no group-by-half interaction $\left(\mathrm{F}_{1,22}=0.001\right.$, n.s. $)$. Figure 4 shows the 'group-by-half' interaction diagram. It can be seen that the groups with dyslexia have lower accuracy than the control group in both halves, both groups have lower accuracy in the second half, and (as reflected by the F value which is very close to zero) that there is no suggestion of interaction between group and half. 


\section{Further analyses}

It has also been suggested that groups with ADHD show greater impulsivity and inability to withhold responses (Barkley, 1994). More recent evidence (Moores and Andrade, 2000) suggests that teenagers with dyslexia do not have difficulty inhibiting a response which has already been initiated. However, we nevertheless considered whether difficulty in inhibiting a response could be an influencing factor on our results, despite none of our participants showing significant evidence of ADHD. A post-hoc analysis of the number of FAs (only) made in the shift attention condition did reveal significant group differences $\left(F_{1,24}=8.09\right.$, $\mathrm{p}<0.01$ ), with the groups with dyslexia producing more FAs than their controls, but the numbers involved were small (2.4\% vs. $1.0 \%$ of the total number of trials in that condition; see also Table 2). Furthermore, mean FA latencies indicated that in focus condition 1, the shift condition, and overall (though not in focus condition 2), the group with dyslexia had slightly slower FA latencies than their controls $\left(\mathrm{F}_{1,20}=5.26, \mathrm{p}<0.05\right.$ in the first focus condition, $\mathrm{F}_{1,11}=0.008$, n.s. in the second focus condition, $\mathrm{F}_{1,24}=1.96$, n.s. in the shift condition). This suggests that FAs were not caused by impulsivity, tallying with the experimenter's impression that the participants with dyslexia were not particularly impulsive and did not have difficulty withholding their responses. Overall, the evidence suggests that any FAs that the group with dyslexia did make over and above their counterparts were unlikely to have been due to any inability to withhold responses.

\section{Discussion of Study 1}

Comparison of the focus attention and shift attention conditions revealed dissociation. For the focus attention tasks the performance of the normally achieving adolescents and those with dyslexia was not significantly different in terms of either accuracy or speed. By contrast, for the shifting attention task, performance of the groups with dyslexia was significantly worse in terms of both accuracy and speed. On the basis of a split-half analysis of the shift attention condition, there was no evidence for a sustained attention deficit in dyslexia. This dissociation between shifting and focused attention tasks is an important finding, albeit perhaps somewhat difficult to interpret, not least because it may have been at least partly due to relatively small sample sizes and a lack of statistical power hiding real differences in focus conditions. Nevertheless, we still considered it interesting that a more statistically reliable effect could be found under shift conditions - a finding not originally hypothesized - and it 
was on the basis of this difference that Study 2 was undertaken. Whilst the findings do support -at least to some extent- an interpretation in terms of difficulties with more attentionally demanding tasks, the attention shifting deficit found was not specifically a rapid shifting deficit ${ }^{6}$, and there are many reasons to believe that the fundamental problem was not in shifting attention at all and could be better explained by a problem in 'central' attention, rather than the componential approach we initially envisaged.

In terms of a capacity model, the shift attention condition is obviously more complex than the focus attention conditions and therefore requires more attentional resources. The shift condition differs from the focus conditions in that (i) the current target has to be kept in memory and (ii) the target has to be changed after each correct hit. The pattern of data suggests that changing the target is not a problem for the dyslexic groups - performance in rapid shifting conditions is equal to that of controls. Maintaining the current target in memory, however, whilst also performing the same detection task required in the focus conditions, does appear to be problematic.

As already briefly discussed in the introduction, the Dyslexia Automatisation Deficit Hypothesis (Nicolson and Fawcett, 1990) proposes that dyslexic children have difficulty in 'skill automatisation' for any skill, motor or cognitive, but that for most skills they learn to mask their incomplete automatisation by a process of 'conscious compensation', thereby achieving apparently near-normal performance, at the expense of greater effort. The DAD neatly accounts for the difficulty of dyslexic people under dual task conditions (Nicolson and Fawcett, 1990; Yap and Van der Leij, 1994), proposing that because the first task is not performed automatically, there are fewer remaining resources to perform the second. In the present experiment, the shift condition could be considered a dual task, in that it requires all the skills required in the focus condition, plus the switching and maintenance of the current target in memory. Thus, if some component of the basic focus attention task is not automatised in dyslexic groups, available resources required to perform the extra components of the shift condition are likely to be scarce. The DAD framework derives from seminal research by Shiffrin and Schneider (1977; Schneider and Shiffrin, 1977). On the basis of long-term training studies on a visual search task, they made a key theoretical distinction between automatic and controlled processing. Automatic processing develops as a result of extensive practice with consistent stimulus-response relations, is not limited by working

\footnotetext{
${ }^{8}$ It should be noted that the current experiment does not rule out an attentional switching deficit with dwell periods of much less than a second - see Hari, Valta and Uutela (1999).
} 
memory capacity or by attention, and is characterised as fast, inflexible and difficult to suppress or unlearn once learned. By contrast, controlled processing occurs in novel situations, or in situations where the stimulus-response mappings have not been sufficiently consistent to foster the development of automatic processing. It is characterised as flexible, capacity limited, attention-demanding, slow and serial. Study 1 results would therefore not be at odds with this hypothesis, assuming a deficit in either automatic shape recognition or automatic responding, for example. Thus, rather than a dissociation per se between focus and shift attention conditions, the apparent difference between groups would reflect an effect based on an automatisation difficulty common to both conditions, yet more troublesome in a condition requiring more resources. Study 2 therefore sought to examine further the idea of an automatic shape recognition deficit in dyslexia.

However, logically there are two alternative hypotheses for an apparent resources deficit in dyslexia. Hypothesis 1 (GRD) is that there is indeed a general resources deficit, and dyslexic groups just have fewer resources available for any task. Hypothesis 2 (DAD) is that dyslexic groups have an automatisation deficit for at least some skills, and so these require more resources than normal for their execution, but that dyslexic people have an equal amount of resources overall. Consequently, if a non-automatised skill is under investigation, increasing task complexity will reach the resource ceiling quicker for dyslexic groups.

Study 2 was therefore designed to distinguish between the two hypotheses. It rests on the following assumptions: first, task performance will suffer a qualitative change when either performance changes from automatic to controlled processing (cf. DAD) or when the resources 'ceiling' is reached. Otherwise performance will decrease in a generally linear fashion with task difficulty. Second, degraded stimuli are processed in a less automatic way by both groups. Under these assumptions, if degraded stimuli are used the two hypotheses make opposite predictions. DAD predicts a marked decrement for the controls but not for the dyslexic participants (since the latter are already processing the stimuli non-automatically). By contrast, the GRD hypothesis predicts a relatively greater deficit for the dyslexic participants than the controls, since the former are already at, or close to, their resource ceiling.

Consequently the above focus/ shift attention paradigm was enhanced by using visually degraded stimuli in addition to normal visibility stimuli. Degraded stimuli require more 
attentional capacity to process and therefore have the property that they use more resources and prevent shape recognition occurring automatically. The GRD hypothesis would therefore predict a group-by-visibility interaction in one direction (participants with dyslexia would have worse performance in degraded conditions whereas controls can cope with the degradation) and the DAD hypothesis in the other direction (controls are affected more by the degradation since it precludes automatic performance of the shape recognition component of the task).

\section{Study 2: Method}

\section{Method}

\section{Participants}

Psychometric data (means and ranges) for the four groups of participants are shown in Table 4. Participants were obtained from the same panel as used in Study 1. Two age groups took part in this study, and we shall refer to the 15 and 19 year old groups with dyslexia as D15 and D19, with the two corresponding normally achieving groups as C15 and C19 respectively. The groups consisted of fourteen participants (13 males, one female) with dyslexia and fourteen normally achieving control participants (6 males, 8 females). Nineteen of the participants had previously taken part in Study 1 around one year earlier. Table 4 shows mean reading/spelling age for each group as assessed at the time they performed this experiment.

All participants were given $£ 5$ for their co-operation.

\section{TABLE 4 ABOUT HERE}

\section{Design}

There were four conditions:

i) Focus condition normal (250 trials):

TARGET: triangles

ii) Shift condition normal (500 trials):

TARGET: triangles and circles alternately

iii) Focus condition degraded (250 trials):

TARGET: squares 
iv) Shift condition degraded (500 trials):

TARGET: squares and diamonds alternately

A repeated measures design was used, counterbalanced so that half the participants in each group experienced the degraded conditions (iii and iv) first and the other half experienced the normal conditions (i and ii) first. Focus attention and shift attention conditions within each visibility condition were always performed in the same order (focus first). This design was used to ensure that any order effects of either practice or fatigue were accounted for across the factor of visibility.

Independent variables were therefore: group (dyslexic $v s$ control), age group (15 vs 19 years), condition (focus $v s$ shift) and visibility (normal $v s$ degraded).

\section{Stimuli}

Owing to the possibility of confusion between the oval and the circle in the previous experiment (which replicated more closely the Akshoomoff and Courchesne (1994) procedure), 4 new shapes were chosen: triangle, square, circle and diamond. All stimuli were of the same colour (grey) so that in degraded conditions the shapes could not be recognised by colour alone. The degraded shapes were created within the Hypercard environment; initially by a random pixel removing procedure so that the shapes were made up of dots, rather than solid, and finally by removal of remaining edges (using the eraser). Pilot work had established that the degraded stimuli used were discriminable, but only with effort. The shapes are shown in Figures 5 and 6.

\section{FIGURES 5 and 6 ABOUT HERE}

\section{Procedure}

The procedure was the same as that used in Study 1 except that the probability of potential target shapes was increased in order to keep the total length of the experiment similar to that in Study 1, whilst preserving a similar number of targets. Potential target shapes (triangle and circle in normal visibility conditions, square and diamond in degraded conditions) now had $20 \%$ probability of occurrence each whilst distractor shapes had $30 \%$ probability of occurrence each. This was possible because time since last switch was no longer being investigated. This manipulation obviously had the effect of decreasing inter-target intervals 
whilst ISIs remained unchanged. A short break was given to each participant between the different visibility conditions.

The whole experiment lasted around 30 minutes.

\section{Results}

The mean probability for hits and FAs are shown in Table 5. It may be seen that the performance overall was good but not perfect, with the mean FA probability ranging from 2$6 \%$ and the mean hit probability ranging from $77 \%$ to $98 \%$. The resulting d' measures are shown in Table 6. Mean response latencies are shown in Table 7.

\section{TABLES 5, 6 and 7 ABOUT HERE}

\section{Accuracy}

The d' measure of accuracy was used as the dependent variable in a four-factor mixed measures analysis of variance investigating effects of group (dyslexic/ control), age (15/19 years), visibility (normal/ degraded) and condition (focus/ shift).

As expected, the effect of visibility was highly significant $\left(F_{1,23}=12.28, p<0.005\right)$, with visually degraded stimuli leading to lower accuracy. The effect of condition was also highly significant $\left(\mathrm{F}_{1,23}=20.38, \mathrm{p}<0.0005\right)$, with shift conditions proving to be most difficult. In addition, the main effects of group and age were significant $\left(F_{1,23}=21.23, p<0.0001\right.$ and $\left.\mathrm{F}_{1,23}=13.48, \mathrm{p}<0.005\right)$, with dyslexic and younger groups being less accurate.

Importantly, a visibility-by-group interaction emerged $\left(\mathrm{F}_{1,23}=8.10, \mathrm{p}<0.01\right)$. This showed that whereas control groups became worse in the degraded conditions, the dyslexic groups' performance was impaired to a lesser extent (see Figure 7). A condition-by-group-by-age interaction was also significant $\left(\mathrm{F}_{1,23}=4.45, \mathrm{p}<0.05\right)$, showing that the older controls had the largest difference in accuracy between focus and shift conditions, but the younger controls had the smallest.

Since, as in Experiment 1 we wanted to exclude potential confounds of differences in attention from our results, the same ANOVA as above was also performed including ADHD 
and IQ scores as covariates. Neither ADHD nor IQ score contributed a significant amount of variance to the model $\left(\mathrm{F}_{1,21}=0.00\right.$ and $\left.\mathrm{F}_{1,21}=0.93\right)$. and the main conclusions that could be drawn from the data remained the same.

\section{FIGURE 7 ABOUT HERE}

\section{Reaction times}

The RT data (Table 4) indicates little apparent effect of group. This impression was confirmed by a five-factor analysis of variance investigating the effect of group, age, response type (correct hit/ FA), condition and visibility on RT. Main effects of group and age were not significant $\left(\mathrm{F}_{1,23}=2.08 \text { and } \mathrm{F}_{1,23}=0.60\right)^{7}$. The effect of visibility was not significant $\left(F_{1,23}=0.15\right)$. Effects of response type and condition were highly significant $\left(F_{1,23}=144.16\right.$, $\mathrm{p}<0.0001$ and $\mathrm{F}_{1,23}=54.88, \mathrm{p}<0.0001$ respectively), with longer latencies for correct hits than for FAs and also longer latencies for shift conditions than focus conditions.

In addition to the significant main effects, there were two significant interactions. A response-by-visibility interaction $\left(\mathrm{F}_{1,23}=8.20, \mathrm{p}<0.01\right)$ arose because hits took longer in the degraded conditions and the FAs tended to be quicker, whereas in normal conditions the differences between FA and correct RTs was less. A response-by-condition interaction also emerged $\left(\mathrm{F}_{1,23}=88.62, \mathrm{p}<0.0001\right)$ showing that $\mathrm{FA}$ responses tended to be very fast overall, but particularly in focus conditions, whereas correct responses took approximately the same time regardless of condition.

\section{Discussion of Study 2}

In summary, therefore, the main finding from Study 2 was a significant group-by-visibility interaction for response accuracy in which it was the control children, rather than the children with dyslexia, who were disproportionately affected by the visual degradation of the stimuli. Thus, the result attesting to the hypotheses for Study 2 is clear. The hypothesis that increasing the attentional load necessary to perform a task will disproportionately affect children with 
dyslexia (a general resources deficit) can be rejected. Dyslexic participants were relatively unaffected by degradation of the stimuli, suggesting that they were performing the shape recognition task non-automatically even with intact stimuli. We do not consider it likely that this lack of detriment to dyslexic groups in degraded conditions is the result of a floor effect, since overall performance was still good, with mean d prime values about 2.5 for both age groups, although we acknowledge that this remains a possibility. The main results are therefore appear to be consistent with the hypothesis of an automatisation deficit in the children with dyslexia.

\section{GENERAL DISCUSSION}

The studies reported here investigated the underlying cause(s) of attentional difficulties in dyslexic children. The studies were designed to minimise the need for linguistic, phonological and auditory processing - known difficulties of dyslexic children. They also avoided the need for eye movements, where again there is evidence of abnormality in some dyslexic children. The results therefore provide a relatively pure index of visual attention in dyslexia, uncontaminated by known processing difficulties.

Study 1 employed a design that allowed three key components of attention - focusing, switching and sustaining - to be investigated separately. Stimuli were simple coloured visual shapes. Overall, in this experiment we failed to detect a deficit in dyslexic participants in the ability to focus attention or to sustain attention, whereas a clear deficit was shown in a condition in which they had to switch attention between two target types. Interestingly, the deficit was not attributable to problems in rapid switching in that, even though the difficulty arose when attention had to be switched, the timecourse suggested that the problem nonetheless occurred in 'central' attention Consequently a second study was undertaken in which an alternative explanation for the switching deficit was sought by considering a capacity-limited model of central attention. We contrasted two hypotheses: (a) that dyslexic teenagers have reduced cognitive resources versus (b) the established hypothesis that they suffer from a general impairment in the ability to automatise basic skills. The visibility-bygroup interaction in Study 2 clearly indicated that a shape recognition automaticity deficit in

\footnotetext{
7 It should be noted, however, that since the number of participants in each group were fairly small, this experiment may not have had sufficient power to reliably detect all between group effects - null results should therefore be interpreted with some caution.
} 
dyslexia accounted best for the data and that a general resources deficit was unsuccessful in doing so.

Thus, the Study 1 dissociation between focus and shift conditions can be explained by dyslexic groups having fewer remaining resources to cope in the shift attention condition, since their shape recognition in neither focus nor shift conditions is automatic. The interaction found in Study 2 can be explained in the same way - since the dyslexic groups' shape recognition was not automatic even with intact stimuli, the stimulus degradation affected their performance less. The findings therefore provide strong support for both the automatisation deficit account of dyslexia. In summary, even though we set out to evaluate the componential framework of visual attention, remarkably, the results of these studies push us back towards the complementary 'resources' framework, and in particular the automatisation deficit framework. Considerable clarification has therefore been achieved by these experiments - in particular by the findings that attention switching and attention focusing systems appear to be relatively normal (as long as eye movements are not required), together with the finding that general resources appear to be normal.

An alternative interpretation of the findings of the present study is that automatisation deficits occur in all modalities, and in all tasks (Nicolson and Fawcett, 1990). Evidence in support of this view derives from a series of experiments (e.g., Nicolson and Fawcett, 1994) looking at simple 'primitive' skills (visual, auditory, speed, memory, motor) that established that the considerable majority of the dyslexic participants had impairments in all the skills (rather than merely a subset). The authors subsequently attributed the generalised automatisation difficulties to abnormal cerebellar function (Nicolson, Fawcett and Dean, 1995; 2001), and have established behavioural, neuroimaging and neuroanatomical evidence directly consistent with the hypothesis (Fawcett, Nicolson, \& Dean, 1996; Finch, Nicolson, \& Fawcett, 2002; Nicolson et al., 1999). Regardless of the specific biological cause, however, Fawcett and Nicolson (2001) argue that the 'cognitive level' description in terms of inefficient central processing provides a parsimonious and plausible explanation of the generality of the symptoms of poor automaticity. In that article, they suggest that there may be inefficiencies in the 'central executive' processing system and argue that although the exact nature and processes of central cognitive processing remain elusive, it seems plausible that these processes (probably involving identification of the stimulus, comparison with a stored target and various decision and response mechanisms) increase in efficiency and sophistication with 
age and experience. In addition, they postulate that since extant data suggest that neither sensory processing nor motor execution phases in themselves are intrinsically slow, it is more likely that the sometimes found slower reaction times in dyslexic children are introduced during the complex central processing stages. It should be stressed that this framework is by no means incompatible with the spatial attentional disorder proposed by Facoetti and colleagues. Lack of automaticity in eye movement control will of course lead to apparent spatial attentional disorders. Such attentional disorders (whether visual, auditory or central) would in turn lead to less coherent data received by the senses, the cerebellum, and the 'central executive' and thus might exacerbate any difficulty in automatising skills, just because the incoming 'signals' are more noisy. Such speculations can only be resolved by further careful multidisciplinary research.

In summary, the studies reported here were designed to investigate both attentional and automatisation abilities of dyslexic children. The results support the hypothesis that, in general, dyslexic children have normal attentional processes in terms of sustaining and switching attention, but that the dyslexic children are not able to recognise (some) shapes automatically. The results therefore provide specific support for the Dyslexia Automatisation Deficit hypothesis (Nicolson and Fawcett, 1990). The findings provide a number of intriguing possibilities for further research.

\section{References}

Akshoomoff, N.A. \& Courchesne, E. (1994). ERP evidence for a shifting attention deficit in patients with damage to the cerebellum. Journal of Cognitive Neuroscience, 6, 388399.

Allport, D.A., Antonis, B. and Reynolds, P. (1972). On the division of attention: A disproof of the single channel hypothesis. Quarterly Journal of Experimental Psychology, 24, 225-235.

American Psychiatric Association (1994). Diagnostic and Statistical Manual of Mental Disorders $4^{\text {th }}$ edition. Washington DC: American Psychiatric Association.

Anderson, J.R. (1982). Acquisition of cognitive skill. Psychological Review, 89, 369-406. 
Augur, J. (1985). Guidelines for teachers, parents and learners. In M.J. Snowling (Ed.), Children's written language difficulties: Assessment and management. London: Routledge. pp. 147-169.

Badian, N.A. (1994). Preschool prediction: Orthographic and phonological skills and reading. Annals of Dyslexia, 44, 3-25.

Barkley, R.A. (1994). Delayed responding and attention deficit hyperactivity disorder: toward a unified theory. In D.K. Routh (Ed.), Disruptive behavior disorders in children: Essays in honor of Herbert Quay (p11-57). New York: Plenum.

Brannan, J.R. \& Williams, M.C. (1987). Allocation of visual attention in good and poor readers. Perception and Psychophysics, 41, 23-28.

Broadbent, D.E. (1958). Perception and Communication. London: Pergamon.

Denckla, M. B., \& Rudel, R. G. (1976). Rapid 'Automatized' naming (R.A.N.). Dyslexia differentiated from other learning disabilities. Neuropsychologia, 14, 471-479.

Dykman, R.A., Ackerman, P.T. \& Oglesby, D.M. (1979). Selective and Sustained Attention in hyperactive, learning-disabled and normal boys. Journal of Nervous and Mental Disease, 167, 288-297.

Everatt, J. (Ed.) (1999). Reading and Dyslexia : Visual and Attentional Processes. London: Routledge

Facoetti, A. \& Molteni, M. (2001). The gradient of visual attention in developmental dyslexia. Neuropsychologia, 39, 352-357.

Facoetti, A., Paganoni, P. \& Lorusso, M.L. (2000). The spatial distribution of visual attention in developmental dyslexia. Experimental Brain Research, 132, 531-538.

Facoetti, A., Paganoni, P., Turatto, M., Marzola, V.\& Mascetti, G.G. (2000). Visual-spatial attention in developmental dyslexia, Cortex, 36, 109-123.

Facoetti, A. \& Turatto, M. (2000). Asymmetrical visual fields distribution of attention in dyslexic children: a neuropsychological study. Neuroscience Letters, 290, 216-218.

Fawcett, A. J. and Nicolson, R. I (2001). Speed and temporal processing in dyslexia. In M Wolf (ed) Dyslexia, Fluency and the Brain. York Press; Maryland.

Fawcett, A.J. and Nicolson, R.I. (1994). Dyslexia in Children: Multidisciplinary Perspectives, Harvester Wheatsheaf.

Fawcett, A.J., Nicolson, R.I. \& Dean, P. (1996). Impaired performance of children with dyslexia on a range of cerebellar tasks. Annals of Dyslexia, 46, 259-283.

Finch, A.J., Nicolson, R.I. \& Fawcett, A.J. (2002). Evidence for a neuroanatomical difference within the olivo-cerebellar pathway of adults with dyslexia. Cortex, in press. 
Fischer, B. \& Weber, H. (1990). Saccadic reaction times of dyslexic and age-matched normal subjects. Perception, 19, 805-818.

Hallahan, D.P., Kauffman, J.M. \& Ball, D.W. (1973). Selective attention and cognitive tempo of low achieving and high achieving sixth grade males. Perceptual and Motor Skills, 36, 579-583.

Hari, R., Valta, M. \& Uutela, K. (1999). Prolonged attentional dwell time in dyslexic adults. Neuroscience Letters, 271, 202-204.

Hazell, P.L., Carr, V.J., Lewin, T.J., Dewis, S.A.M., Heathcote, D.M. and Brucki, B.M. (1999). Effortful and automatic processing in boys with ADHD and Specific Learning Disorders. Journal of Child Psychology and Psychiatry, 40, 275-86.

Jorm, A.F., Share, D.L., McLean, R. and Matthews, D. (1986). Cognitive factors at school entry predictive of specific reading retardation and general reading backwardness: A research note. Journal of Child Psychology and Psychiatry and Allied Disciplines, 27, 45-54.

Kahneman, D. (1973). Attention and Effort. Englewood Cliffs, NJ: Prentice-Hall.

Milberg, V.W., Whitman, R.D. \& Galpin, R. (1981). Selective attention and laterality in good and poor readers. Cortex, 17, 571-82.

Mirsky, A.F., Fantie, B.D. \& Tatman, J.E. (1995). Assessment of attention across the lifespan. In R.L.Mapou \& J.Spector (Eds.) Clinical Neuropsychological Assessment: A Cognitive Approach. New York: Plenum, pp17-48.

Moores, E. \& Andrade, J. (2000). Ability of dyslexic and control teenagers to sustain attention and inhibit responses. European Journal of Cognitive Psychology, 12, 520540 .

Navon, D. (1984). Resources: a theoretical soup-stone? Psychological Review, 91, 216-234.

Nicolson, R. I., \& Fawcett, A. J. (2000). Long-term learning in dyslexic children. European Journal of Cognitive Psychology, 12, 357-393.

Nicolson, R.I. \& Fawcett, A.J. (1990). Automaticity: A new framework for dyslexia research? Cognition, 35, 159-182.

Nicolson, R.I. and Fawcett, A.J. (1994). Comparison of deficits in cognitive and motor skills in children with dyslexia. Annals of Dyslexia, 44, 147-164.

Nicolson, R.I., Fawcett, A.J., Berry, E.L., Jenkins, I.H., Dean, P. \& Brooks, D.J. (1999). Association of abnormal cerebellar activation with motor learning difficulties in dyslexic adults. Lancet, 352, 1662-1667. 
Nicolson, R.I., Fawcett, A.J. \& Dean, P. (1995). Time estimation deficits in developmental dyslexia: Evidence of cerebellar involvement. Proceedings of the Royal Society of London, 259, 43-47.

Nicolson, R.I., Fawcett, A.J. \& Dean, P. (2001). Developmental dyslexia: The Cerebellar Deficit Hypothesis. Trends in Neurosciences, 24, 508-511.

Norman, D. A. (1968). Toward a theory of memory and attention. Psychological Review, 75, 44-64.

Pearson, D.A. \& Lane, D.M. (1990). Reorientation in hyperactive and non-hyperactive children: Evidence for developmentally immature attention? In J.T. Enns (ed.) The Development of Attention: Research and Theory. Elsevier Science: Holland.

Pelham, W. (1979). Selective attention deficits in poor readers? Dichotic listening, speeded classification, and auditory and visual central and incidental learning tasks. Child Development, 50, 1050-61.

Posner, M.I. and Petersen, S.E. (1990). The attentional system of the human brain. Annual Review of Neuroscience, 13, 25-42.

Reason, R. (1999). ADHD: A psychological response to an evolving concept. Journal of Learning Disabilities, 32, 85-91.

Schneider, W. \& Shiffrin, R.M. (1977). Controlled and automatic human information processing I: Detection, search and attention. Pyschological Review, 84, 1-66.

Shaywitz, S.E., Fletcher, J.M. \& Shaywitz, B.A. (1994). Issues in the definition and classification of attention deficit disorder. Topics in Language Disorders, 14, 1-25.

Shiffrin, R.M. and Schneider, W. (1977). Controlled and automatic human information processing II. Perceptual learning, automatic attending, and a general theory. Psychological Review, 84, 127-190.

Snowling, M. (1987). Dyslexia: A Cognitive Developmental Perspective. Blackwell, Oxford.

Stanovich, K.E. (1988). Explaining the differences between the dyslexic and the garden variety poor reader: The phonological-core variable-difference model. Journal of Learning Disabilities, 21, 590-612.

Swets, J. A. (1964). Signal detection and recognition by human observers: Contemporary readings. New York; London: Wiley.

Vellutino, F.R. (1979). Dyslexia: Theory and Research. Cambridge, MA: MIT Press.

Wechsler, D. (1976). Wechsler Intelligence Scale for Children - $3^{\text {rd }}$ edition (WISC III). Sidcup, UK; The Psychological Corporation, Europe.

Wechsler, D. (1993). Wechsler Objective Reading Dimension. London: The Psychological Corporation. 
Wolf, M., \& Bowers, P. G. (1999). The double-deficit hypothesis for the developmental dyslexias. Journal of Educational Psychology, 91, 415-438.

World Federation of Neurology (1968). Report of research group on dyslexia and world illiteracy. Dallas: WFN.

Yap, R.L. and Van der Leij, A. (1994). Testing the automatisation hypothesis of dyslexia via a dual task paradigm. Journal of Learning Disabilities, 27, 660-65. 


\begin{tabular}{|c|c|c|c|c|c|}
\hline Group & $\mathbf{n}$ & $\begin{array}{c}\text { Mean Age } \\
\text { (years) }\end{array}$ & $\begin{array}{c}\text { Mean IQ } \\
\text { (score) }\end{array}$ & $\begin{array}{c}\text { Mean RA } \\
\text { (years) }\end{array}$ & $\begin{array}{c}\text { Mean ADHD } \\
\text { (no. symptoms } \\
\text { reported) }\end{array}$ \\
\hline D14 & 7 & $14.1(13.2-15.0)$ & $108(96-126)$ & $12.1(8.3-15)^{\dagger}$ & $1.29(0-6)$ \\
\hline $\mathbf{C 1 4}$ & 6 & $14.5(13.8-15.2)$ & $115(101-124)$ & $15.1(14.0-17+)$ & $0.17(0-1)$ \\
\hline D18 & 7 & $18.3(16.5-20.1)$ & $117(101-133)$ & $13.3(14.0-17+)$ & $0.29(0-1)$ \\
\hline $\mathbf{C 1 8}$ & 8 & $18.2(17.0-18.8)$ & $114(96-122)$ & $17+(17.0-17+)$ & 0 \\
\hline
\end{tabular}

Table 1. Psychometric mean data for the four groups of subjects (Range shown in parentheses)

${ }^{\dagger}$ Two of the participants in this group had caught up with their reading since time of diagnosis. These were children of high IQ. Their spelling ages remained significantly lowered. 


\begin{tabular}{|c|c|c|c|c|c|c|c|c|c|}
\hline \multicolumn{9}{|c|}{ Condition } \\
\hline \multirow{2}{*}{ Group } & \multicolumn{3}{|c|}{ Focus 1 } & \multicolumn{3}{c|}{ Shift } & \multicolumn{3}{c|}{ Focus 2 } \\
\cline { 2 - 11 } & $d^{\prime}$ & Hits & FAs & $d^{\prime}$ & Hits & FAs & d' $^{\prime}$ & Hits & FAs \\
\hline D14 & $4.06_{(0.39)}$ & 72 & 2.3 & $3.69_{(0.42)}$ & 74 & 2.1 & $5.29(0.27)$ & 82 & 0.4 \\
\hline C14 & $4.46_{(0.42)}$ & 81 & 1.8 & $4.05_{(0.45)}$ & 81 & 1.6 & $5.58_{(0.29)}$ & 85 & 0.1 \\
\hline D18 & $5.53_{(0.39)}$ & 87 & 1.0 & $3.88_{(0.42)}$ & 84 & 3.2 & $6.02(0.27)$ & 91 & 0.5 \\
\hline C18 & $6.44_{(0.36)}$ & 93 & 0.5 & $5.43_{(0.39)}$ & 91 & 0.8 & $6.03(0.25)$ & 91 & 0.2 \\
\hline
\end{tabular}

Table 2. Mean proportion (as a percentage) of hits and FAs of the four groups of participants (collapsed over time since last hit). Also resulting mean accuracy $\left(d^{\prime}\right)$ with standard errors in parentheses 


\begin{tabular}{|c|c|c|c|}
\cline { 2 - 4 } \multicolumn{1}{c|}{} & \multicolumn{3}{c|}{ Condition } \\
\cline { 2 - 4 } \multicolumn{1}{c|}{} & Focus 1 & Shift & Focus 2 \\
\hline D14 & $650(5)$ & $639(2)$ & $638(2)$ \\
\hline C14 & $596(4)$ & $584(2)$ & $603(2)$ \\
\hline D18 & $609(4)$ & $604(2)$ & $589(2)$ \\
\hline C18 & $543(2)$ & $549(2)$ & $556(2)$ \\
\hline
\end{tabular}

Table 3. Mean RTs (ms) of the four groups of participants (collapsed over time since last hit). Standard errors in parentheses. 
Table 4. Psychometric data for the four groups of participants (range shown in parentheses).

\begin{tabular}{|c|c|c|c|c|c|}
\hline Group & $\mathbf{n}$ & $\begin{array}{c}\text { Mean Age } \\
\text { (years) }\end{array}$ & $\begin{array}{c}\text { Mean IQ } \\
(\text { score })\end{array}$ & $\begin{array}{c}\text { Mean RA } \\
(\text { years })\end{array}$ & $\begin{array}{c}\text { Mean ADHD } \\
\text { (no. symptoms } \\
\text { reported) }\end{array}$ \\
\hline D15 & 8 & $14.6(13.5-15.2)$ & $113(96-134)$ & $13.4(9.3-17)^{\dagger}$ & $1.0(0-6)$ \\
\hline C15 & 9 & $15.0(13.8-16.0)$ & $116(101-129)$ & $16.2(14.0-17+)$ & $0.1(0-1)$ \\
\hline D19 & 6 & $19.0(17.3-20.9)$ & $115(101-131)$ & $12.8(9.3-16.0)$ & $0.3(0-1)$ \\
\hline C19 & 5 & $18.8(17.8-19.5)$ & $114(96-130)$ & $17+$ & 0.0 \\
\hline
\end{tabular}

${ }^{\dagger}$ The anomalous score of 17 derives from one dyslexic participant who has been diagnosed some years previously and had subsequently made exceptional progress in reading. Nonetheless, his spelling was very poor (spelling age of 11:2 at the time of the study). 
Table 5. Mean percent of hits and false alarms (FA) for the four groups in each of the conditions. Standard Errors in parentheses.

\begin{tabular}{|c|c|c|c|c|c|c|c|c|}
\hline & \multicolumn{4}{|c|}{ Focus } & \multicolumn{3}{c|}{ Shift } \\
\hline & \multicolumn{2}{|c|}{ Normal } & \multicolumn{2}{c|}{ Degraded } & \multicolumn{2}{c|}{ Normal } & \multicolumn{2}{c|}{ Degraded } \\
\hline & Hit & FA & Hit & FA & Hit & FA & Hit & FA \\
\hline D15 & $85_{(2.5)}$ & $5_{(0.7)}$ & $87_{(2.4)}$ & $6_{(0.5)}$ & $83_{(2.7)}$ & $5_{(0.6)}$ & $77_{(2.1)}$ & $5_{(0.5)}$ \\
\hline C15 & $89_{(2.5)}$ & $3_{(0.7)}$ & $89_{(2.4)}$ & $4_{(0.5)}$ & $89_{(2.7)}$ & $3_{(0.6)}$ & $82_{(2.1)}$ & $4_{(0.5)}$ \\
\hline D19 & $88_{(2.9)}$ & $4_{(0.8)}$ & $91_{(2.7)}$ & $4_{(0.6)}$ & $88_{(3.1)}$ & $5_{(0.7)}$ & $86_{(2.4)}$ & $5_{(0.6)}$ \\
\hline C19 & $98_{(3.2)}$ & $2_{(0.9)}$ & $9_{(3.0)}$ & $4_{(0.7)}$ & $9_{(3.4)}$ & $2_{(0.8)}$ & $9_{(2.6)}$ & $3_{(0.7)}$ \\
\hline
\end{tabular}


Table 6. Mean results of accuracy in each of the conditions for each of the four groups (standard errors shown in parentheses)

\begin{tabular}{|l|l|l|l|l|}
\hline & \multicolumn{3}{|c|}{$\mathrm{d}^{\prime}$} \\
\hline & \multicolumn{2}{|c|}{ Focus } & \multicolumn{2}{c|}{ Shift } \\
\hline & Normal & Degraded & Normal & Degraded \\
\hline D15 & $2.8_{(0.24)}$ & $2.8_{(0.19)}$ & $2.6_{(0.20)}$ & $2.4_{(0.09)}$ \\
\hline C15 & $3.2_{(0.20)}$ & $3.1_{(0.19)}$ & $3.3_{(0.24)}$ & $2.8_{(0.09)}$ \\
\hline D19 & $3.0_{(0.27)}$ & $3.2_{(0.22)}$ & $2.9_{(0.23)}$ & $2.8_{(0.11)}$ \\
\hline C19 & $4.6_{(0.30)}$ & $3.8_{(0.24)}$ & $3.7_{(0.25)}$ & $3.2_{(0.12)}$ \\
\hline
\end{tabular}


Table 7. Mean results for $R T$ ( $m s)$ in each of the conditions for each of the four groups. Standard Errors shown in parentheses.

\begin{tabular}{|l|l|l|l|l|l|l|l|l|}
\hline & \multicolumn{4}{|c|}{ Focus } & \multicolumn{4}{c|}{ Shift } \\
\hline & \multicolumn{2}{|c|}{ Normal } & \multicolumn{2}{|c|}{ Degraded } & \multicolumn{2}{c|}{ Normal } & \multicolumn{2}{c|}{ Degraded } \\
\hline & Hit & FA & Hit & FA & Hit & FA & Hit & FA \\
\hline D15 & $627_{(17)}$ & $376_{(33)}$ & $657_{(17)}$ & $364_{(35)}$ & $606_{(25)}$ & $536_{(53)}$ & $655_{(17)}$ & $520_{(27)}$ \\
\hline C15 & $596_{(17)}$ & $314_{(33)}$ & $611_{(17)}$ & $375_{(35)}$ & $571_{(25)}$ & $535_{(53)}$ & $597_{(17)}$ & $531_{(27)}$ \\
\hline D19 & $607_{(20)}$ & $410_{(38)}$ & $638_{(20)}$ & $316_{(40)}$ & $570_{(29)}$ & $550_{(61)}$ & $621_{(20)}$ & $515_{(31)}$ \\
\hline C19 & $555_{(22)}$ & $389_{(42)}$ & $59_{(21)}$ & $308_{(44)}$ & $606_{(31)}$ & $480_{(66)}$ & $612_{(21)}$ & $478_{(34)}$ \\
\hline
\end{tabular}




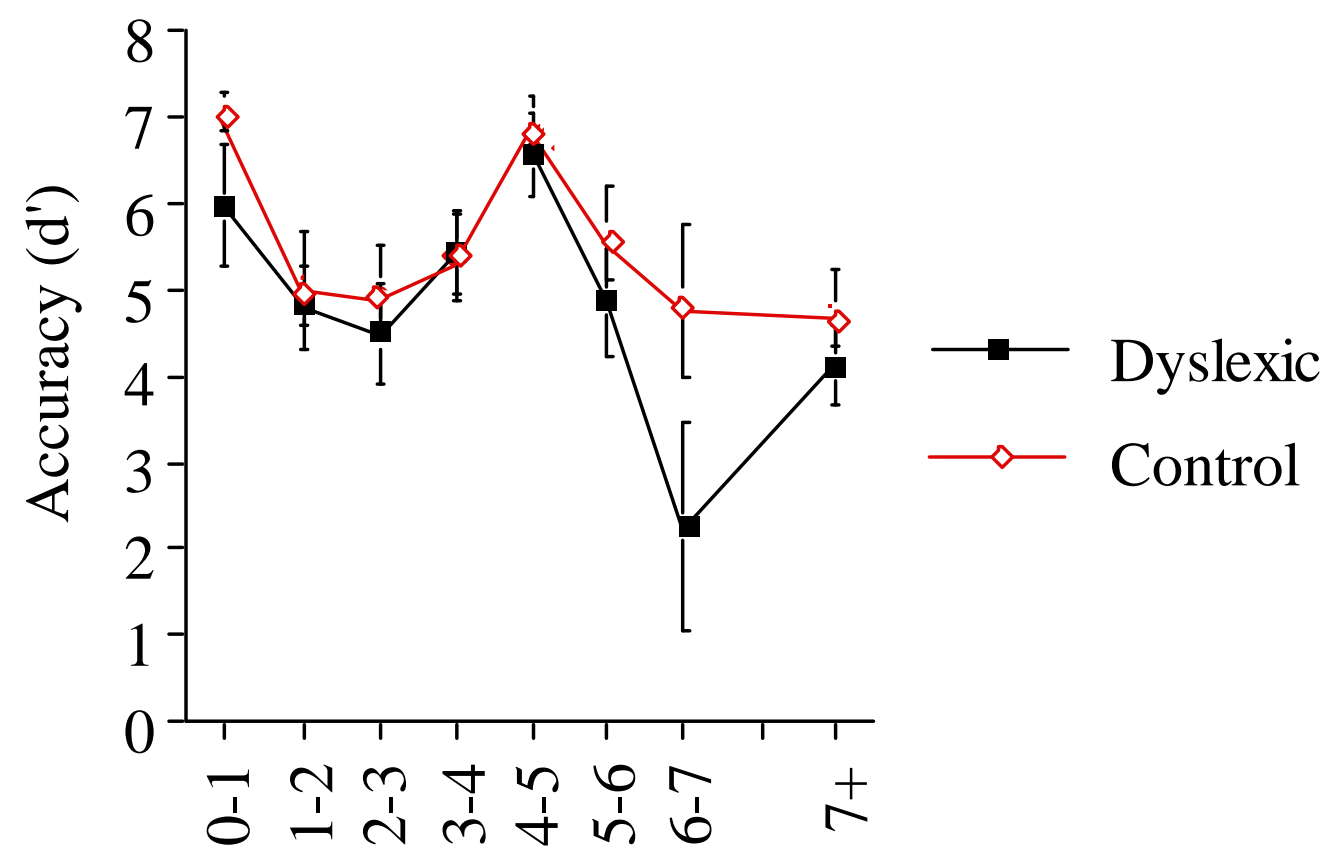

Time Bands (seconds)

Figure 1. Focus Condition 1. Accuracy as a function of time since the last correct hit. Mean Group Results (standard error bars shown) 


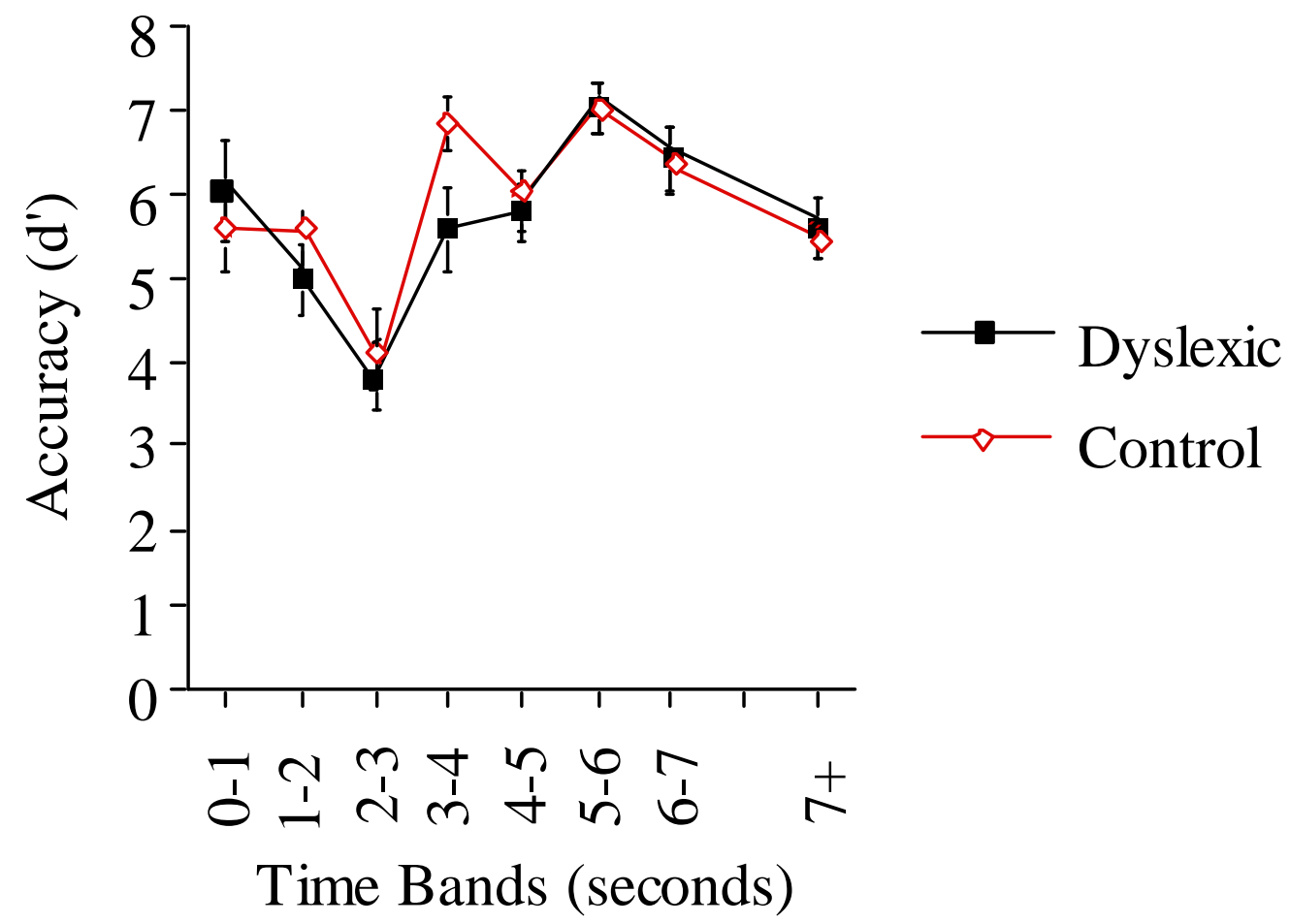

Figure 2. Focus Condition 2. Accuracy as a function of time since the last correct hit. Mean Group Results (standard error bars shown) 


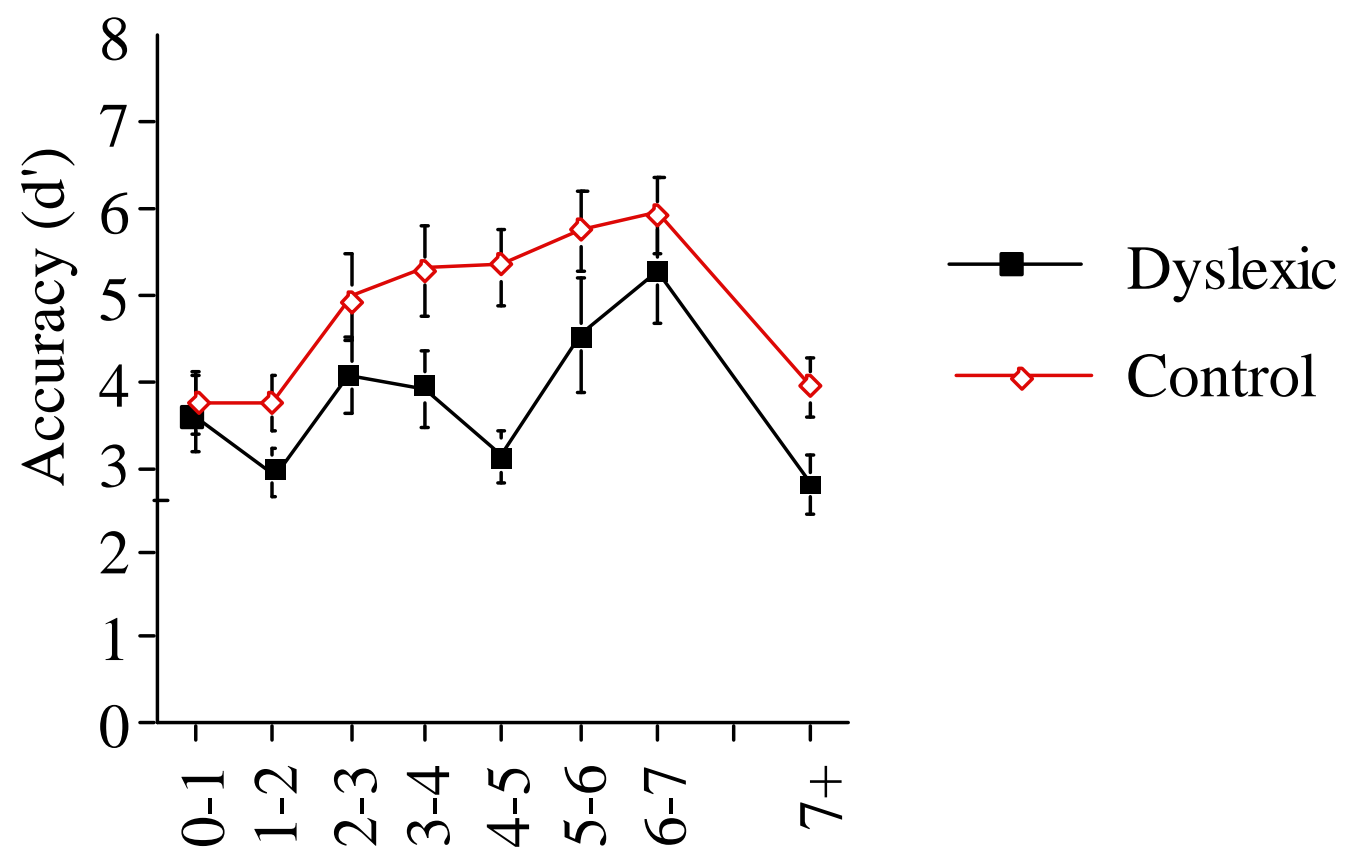

Time Bands (seconds)

Figure 3. Shift condition. Accuracy as a function of time since the last correct hit. Mean Group Results (standard error bars shown) 


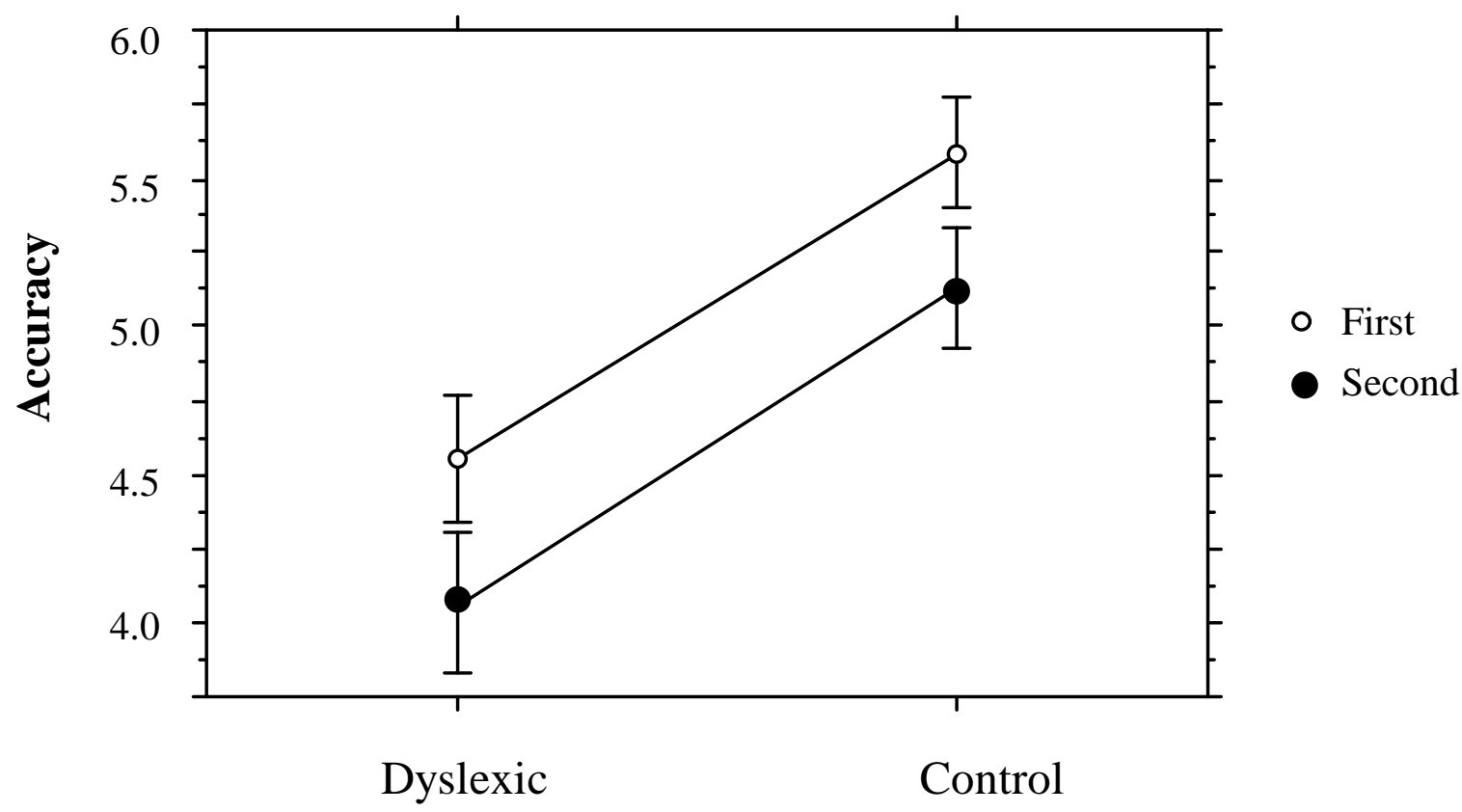

Figure 4. Shift Condition: split-half analysis interaction diagram (standard errors shown). Mean accuracy (d') collapsed over time since last switch 
Figure 5. The shapes used in the normal visibility conditions.
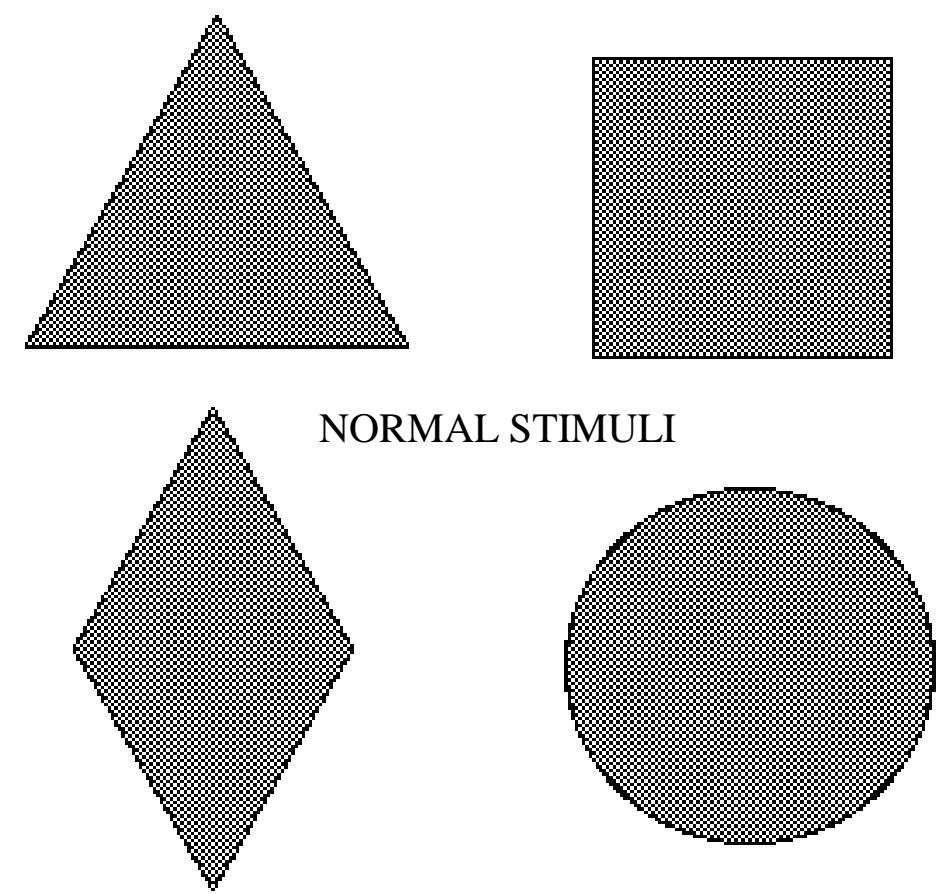
Figure 6. The shapes used in the degraded visibility conditions.
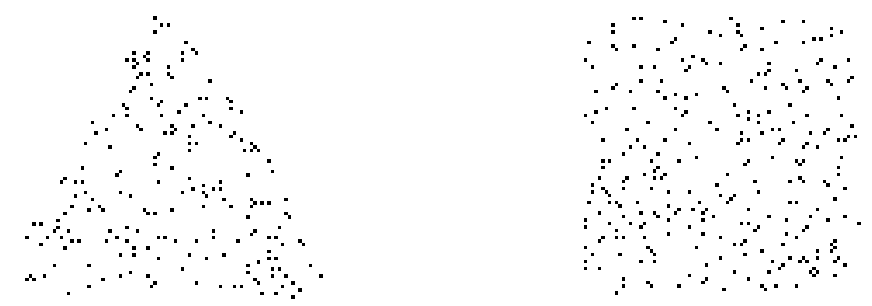

DEGRADED STIMULI
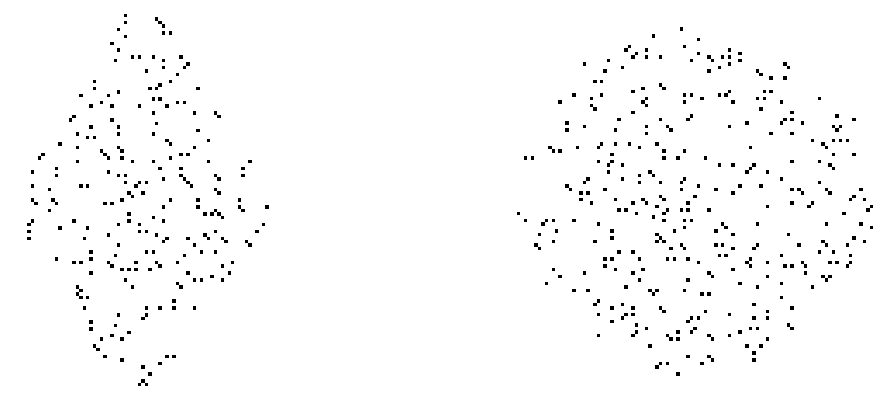


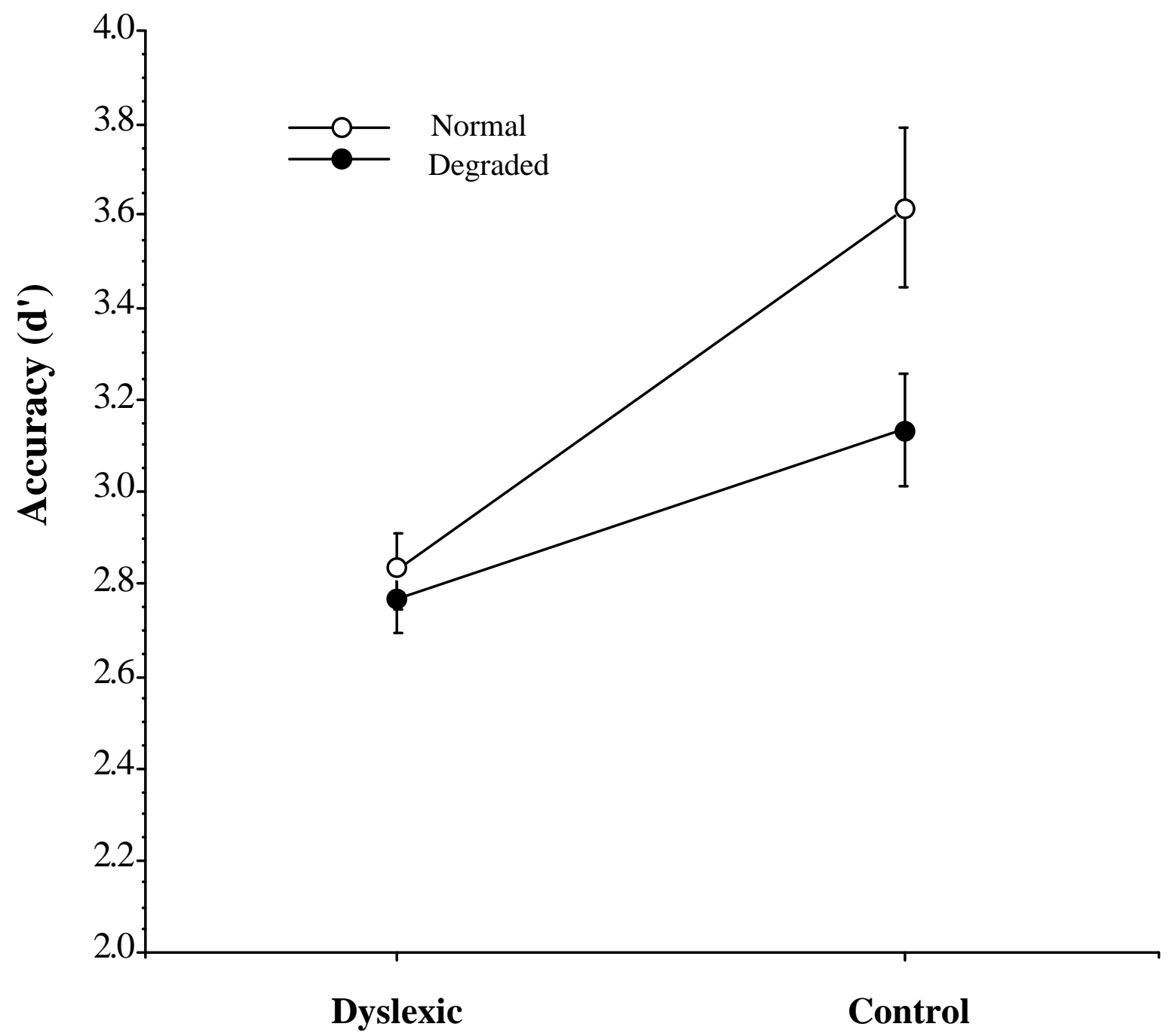

Figure 7. Plot showing the significant visibility-by-group interaction (collapsed over age groups). Standard error bars are shown. 